\title{
Obituary
}

\section{Philip S Holzman: A Legacy of Wisdom and Optimism}

\author{
Neuropsychopharmacology (2005) 30, 1036-1038. \\ doi: | 0.1038/sj.npp. 1300636
}

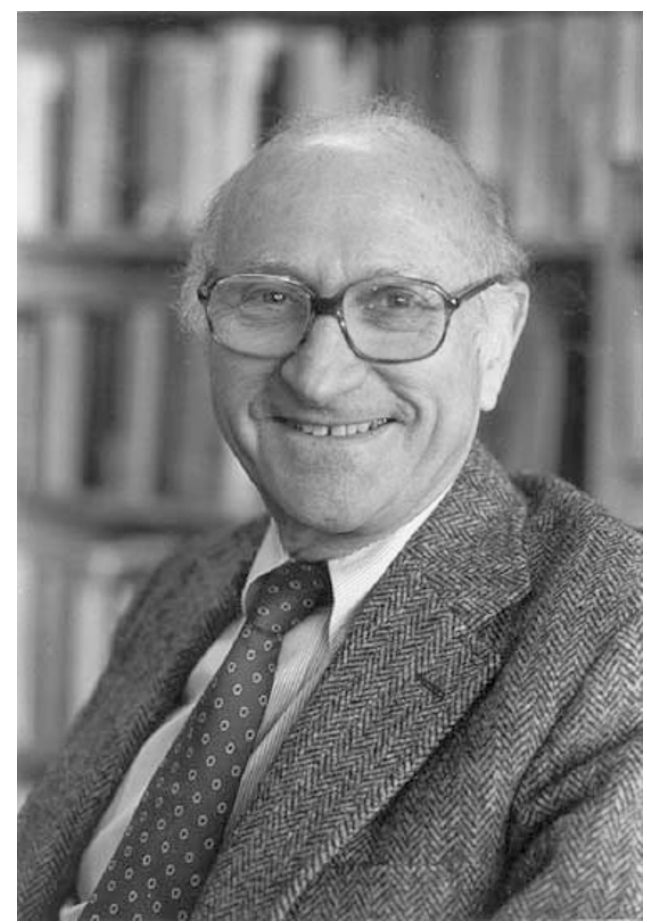

Philip S Holzman, PhD, 1922-2004

Dr Philip S Holzman, a pre-eminent figure in the world of schizophrenia research, died on 1 June 2004, at the age of 82. Dr Holzman is survived by Ann Holzman, his wife of 58 years; his children Natalie Bernardoni, Carl Holzman and Paul Holzman; his son-in-law Gene Bernardoni; his daughter-in-law Mira Kopell; his grandchildren Joseph, Neena and Daniel; and his sister, Sylvia Steinbrock. A memorial celebration of his life was held on Saturday, 23 October 2004 at the American Academy of Arts and Sciences in Cambridge, MA.

The membership of the ACNP is intimately familiar with the extraordinary breadth and significance of Dr Holzman's contributions to research on the major psychoses, especially schizophrenia. He has been such a ubiquitous presence for so long that it seems like he has been with us, doing schizophrenia research, forever. However, in fact, he had already had two long, entirely different, and very distinguished careers before he began his research in schizophrenia-one as a clinical psychologist immersed in psychoanalytic metapsychology and treatment, and one as a researcher who characterized and probed individual differences in perceptual organization. During 22 years at the Menninger Foundation, he co-authored a book on psychoanalytic technique, validated a Rorschach determinant as a predictor of risk for suicide, and wrote extensively on clinical issues - process in psychotherapy supervision, therapeutic elements of the hospital milieu, and the psychodynamic meaning of procrastination, to mention just a few. He was one of a handful of clinical psychologists to receive full psychoanalytic training within the psychoanalytic establishment. He became a training and supervising analyst in Topeka and continued to practice and teach in Chicago and Boston. His earliest mentors were Gardner Murphy, Karl Menninger, David Rapaport, Merton Gill, and Roy Schafer. During the same period, he embarked on an ambitious program of research with George Klein and Herbert Schlesinger on the effects of motivation, drive regulation, memory, defenses, and reality constraints on different styles of regulating cognition. From this body of work, terms such as cognitive controls, cognitive styles, and perceptual or cognitive attitudes became part of the lexicon of general psychology. For anyone who knew Dr Holzman, it will come as no surprise that these two seemingly disparate interests - the humanistic world of the clinician and the empirical world of the researcher-continued to coexist throughout his career.

It was, in a sense, serendipity that the focus of Dr Holzman's research shifted to schizophrenia. In 1967, Joseph Zubin and Charles Shagass, co-chairs of the program committee of the American Psychopathological Association, asked Dr Holzman to assess the status of research on perception and psychosis for the 1968 annual meeting. His track record of research in the area of perception made him an obvious choice, and because he had carried out no research on schizophrenia yet was a seasoned clinician, it was the ideal opportunity to give this area of research a fresh look. That review was a pivotal event that changed the course of his career. He moved to the University of Chicago, where he launched a far-reaching program of schizophrenia research with the strong support of Daniel X Freedman. His initial foray into empirical research on schizophrenia showed continuity with his previous research and clinical background, but it also charted the new directions he had identified in his APPA overview of perceptual aspects of psychopathology. He examined whether the stable organizing cognitive strategies that are found in individuals without serious psychopathology are also characteristic of individuals with psychotic disorders. He probed psychomotor impairments. He developed a metric for quantifying and identifying the kinds of thought disorder associated with the various psychoses. Having determined that one of the most consistent findings in the schizophrenia literature was vestibular hyporesponsivity, he embarked on a study of the vestibular system. It was in the context of that study of vestibular reactivity that the completely unexpected finding of eye tracking dysfunction (ETD) was discovered, and that was just his first set of studies on schizophrenia. The first report on ETD was actually Dr Holzman's first empirical 
study of schizophrenia. In fact, all of his work on schizophrenia was undertaken after the age of 50. Moreover, $40 \%$ of his scholarly writings were published in just the 12 years after he supposedly 'retired'.

Dr Holzman had an extraordinarily distinguished career in schizophrenia research. As Steven Matthysse said in the preface to the festschrift in honor of Holzman's return to full-time research, 'Philip Holzman has explored experimental psychopathology with a depth and breadth unequalled in our time.' He is probably most widely known for his seminal observations about abnormal smooth pursuit eye movements or ETD in schizophrenics and their biological first-degree relatives. Holzman and his colleagues noted that the eyes of schizophrenic subjects lag behind when following a moving target and they compensate for this by generating, rapid movements to bring the target back onto the fovea. He and his colleagues quickly ruled out a possible role for antipsychotic medication by observing that drug-free and/or drug-naïve patients also showed ETD. He went on to demonstrate, moreover, that about $40 \%$ of clinically unaffected first-degree relatives of schizophrenics showed ETD, which suggested that this trait might be a marker or endophenotype for schizophrenia.

To pursue this possibility further, Dr Holzman investigated ETD in monozygotic (MZ) and dizygotic (DZ) twin pairs who were discordant for clinical schizophrenia. He observed that concordance for ETD was twice as high in MZ twins as in DZ twins, a result consistent with genetic transmission of ETD. In subsequent studies that examined the familial distribution of ETD and schizophrenia, he showed that ETD and schizophrenia may be transmitted as independent manifestations of an autosomal dominant trait. Observing that ETD occurred when a subject pursued a moving target, Holzman and his colleagues probed its physiology through studies of the motion processing system in the brain. They postulated that an impaired capacity to integrate motion signals, rather than a general visual defect, played a role in ETD. Schizophrenic subjects and their first-degree relatives were found to have raised motion discrimination deficits, which were, in turn, correlated with sluggish initiation of smooth pursuit. Based on lesion studies, Dr Holzman postulated that the motion sensitive areas of the parietal lobe, that is, the medial temporal (MT) and medial superior temporal (MST) regions, and an extended network of connections that included frontal and prefrontal areas, were among the processes underlying ETD in schizophrenia.

Among his accomplishments was using the scientific method to carefully uncover the genetic components to its pathophysiology. He was among the first investigators to appreciate the importance of studying the biological relatives of schizophrenics. At the time that he began his work, family members were generally considered of interest only from the standpoint of whether they were ill, with the notable exception of Norman Garmezy, who recognized that the determinants of resilience warranted investigation in their own right. Holzman realized that the occurrence of the same behaviors in patients and their well relatives meant that the behaviors could not be consequences of pharmacologic treatment for the illness, secondary effects of acute psychosis, or a manifestation of the generalized deficits that accompany schizophrenic disorganization. He also realized that the presence of the same behaviors in well relatives and in patients must have significance. He pioneered the strategy, now widely adopted throughout the field, of considering such co-familial traits as pleiotropic, more penetrant expressions of schizophrenia genes. In addition to their potential value as probes of brain function that are easier to dissect physiologically than the florid symptoms of psychosis, these traits provide a way of provisionally identifying nonpenetrant gene carriers and improve the power to detect linkage to schizophrenia susceptibility genes.

Born in New York City in 1922, Dr Philip Holzman graduated from the College of the City of New York in 1943 and completed a doctoral degree from the University of Kansas in 1952. After working at the Menninger Foundation and the University of Chicago, he joined the Faculty of Arts and Sciences at Harvard University and the Department of Psychiatry at Harvard Medical School. In 1977, he founded the Psychology Research Laboratory at McLean Hospital in Belmont, MA, and became an integral part of the research group organized by Seymour Kety at the Mailman Research Center. Dr Holzman was the Director of the Psychology Research Laboratory at the time of his death.

$\mathrm{He}$ was the recipient of many prestigious awards and honors, including the Lieber Prize from the National Alliance for Research on Schizophrenia and Depression (NARSAD), the Gold Medal Award for Lifetime Achievement from the American Psychological Foundation, the Joseph Zubin Award from the Society for Research in Psychopathology, the Stanley R Dean Award from the American College of Psychiatrists, the William K Warren Award from the International Congress of Schizophrenia Research, the Townsend Harris Medal of the City College of New York and, most recently, he was the first recipient of the Alexander Gralnick Research Investigator Award. He was a member of the Institute of Medicine of the National Academy of Sciences, the American Academy of Arts and Sciences, the Board of Trustees of the Menninger Foundation, the Scientific Advisory Committee of the Health Program of the John and Catherine $\mathrm{T}$ Mac Arthur Foundation, and a member of the Board of Scientific Counselors of NARSAD.

One of Dr Holzman's most lasting legacies to the scientific community was his endless capacity for collaborating with colleagues and for mentoring students. All of his work involved collaborations that he forged with a diverse array of experts - from otolaryngologists, physiologists, brain imagers, statisticians, psychiatrists, molecular, statistical, and theoretical geneticists, experts in vision sciences and memory, engineers, to other psychologists. In his work at the University of Chicago and at Harvard University, he was joined by a cadre of students and postdoctoral fellows, who were the fortunate beneficiaries of his wisdom and his generativity. Many of these students have gone on to accomplished research careers and direct laboratories all over the world. His door was always open and he always welcomed everyone to come in, with a twinkle in his eye and a beaming smile. It did not matter how busy he was or how much work he had to do. His actions showed how much he genuinely believed in letting 'a thousand flowers bloom'. His warmth, humor, generosity, and generativity are unrivalled. 
An appreciation of the personal qualities that made Dr Holzman so special must include his contagious joy. He had a magnetic presence - he brought endless optimism, unflagging energy, and infectious enthusiasm to everything he didwhether it was his own life, his family, his work, telling a good joke, sharing a fine meal, listening to music, practicing Italian, running and swimming, or completing the New York Times crossword puzzle every day. He was even confident that the Red Sox would one day beat the Yankees and then win the World Series. As usual, he was right.

Dr Holzman loved to find a reason to tell one of his jokes or stories. There is one in particular that epitomizes his attitude about process in science and in life. Years ago the English and French governments decided that it was not efficient to have to cross the English Channel by boat only, and that a tunnel should be built. They asked for bids and about 10 companies submitted one. All of the bids were over 150 million pounds except for one. The Goldstein brothers, who had a business on Delancey Street, made a bid of 10000 pounds. The commissioners who had to decide on awarding the contract held a hearing and asked each company to explain how it had arrived at its bid. When they got to the Goldstein brothers, the commissioner told them that their bid was orders of magnitude lower than all the other bids and asked how they could possibly build the tunnel so inexpensively. Goldstein replied, 'That's easy. I start digging from Calais. My brother starts digging from Dover. We meet in the middle and you have a tunnel.' The commissioner asked, 'But what if you don't meet?' Goldstein replied, 'Then you have two tunnels!'

We will miss the richness and complexity of his scientific insights and the intricacies of the dialectical process he used to frame his hypotheses and scientific experiments. We will miss his unwavering commitment to schizophrenia research and his enduring belief that the scientific method will advance our understanding of this very complex disorder. He was a beloved friend and colleague, nurturing mentor, and intrepid researcher who enriched generations of scholars. His extraordinary vision, humor, relentless enthusiasm and indomitable optimism inspired all of us who had the privilege of working with him. His many contributions to the fields of psychology, psychiatry and cognitive neuroscience, including his love of teaching others, will serve as a lasting legacy to ACNP and to the entire scientific community.

Deborah L Levy and Francine M Benes 